\title{
Teaching Reform and Practice of EST Writing from the Perspective of Output Driven
}

\author{
Ding zhirui ${ }^{1, a}$, Wu jin ${ }^{2, b}$ \\ ${ }^{1}$ Foreign Language School, Jilin Agricultural University, Changchun, 130118, China; \\ ${ }^{2}$ Foreign Languages Department, Jilin University of Finance and Economics, \\ Changchun, 130117, China; \\ a41714453@qq.com, b41714453@qq.com
}

Keywords: Output Driven; Classroom Practice; Student Body

\begin{abstract}
Most of the subjects faced by scientific and technical English writing are the learners who already have considerable English knowledge and more advanced language ability. In the course of teaching, teachers should change their roles according to specific circumstances. The theory of output driven hypothesis is adopted to design the content of practice rationally, and the output is used to drive input, so that learning can be carried out effectively.
\end{abstract}

\section{The "output drive" hypothesis}

Language learning has always been an important part of the learning process. It is essentially a process in which input and output interact with each other. This is even more pronounced for the acquisition of a second language. Therefore, the research on the theory and practice of "input" and "output" has been an important research area in the field of second language acquisition. In the 80s of last century, Krashen, an American linguist, put forward the theory of language input". Krashen (1982) provides five hypotheses, in which he believes that the input hypothesis is the most important one as it touches upon directly the most fundamental question of second language acquisition (SLA). (Yang ye, 2010) The theory holds that the process of language acquisition is actually a process in which language symbols and information are constantly accepted and understood by learners. The acquisition of language cannot be achieved by rote memorization, but by truly understanding the accepted input, which make us really acquired the language. Thus, the importance of comprehensible input, which has become a very important concept in the twolanguage acquisition theory, has provided us with new ideas and perspectives for the development of foreign language teaching. However, Krashen's language input theory has its own limitations. He emphasizes input excessively and regards output as a natural result of input. It holds that output has no direct effect on language acquisition.

In 1985, another linguist, Swain, proposed the output hypothesis". He believes that not only input but also output can play an important role in language acquisition. However, Swain emphasized too much on the output, and believed that language input for language acquisition only played a supporting role. Input of language is a carrier in the process of language acquisition, which cannot become the ultimate means of language acquisition. He supported that only through the output process, the language expression and practice, can make learners really acquire language. It is not difficult to see that because of the research background of Canadian French immersion teaching himself, Swain's theory only emphasizes that the learning process of the output are conscious of inspection and monitoring for its output. However, for those language learners who are still lack of target language environment, his theory cannot provide effective solutions to the problems such as how to self-monitoring and evaluation. In fact, from the law of language learning, "input" and "output" have their specific functions, and both of them need to be paid enough attention to in the two aspects. Among them, "input" can be said to be the basis of "output", and it is 
in the first place. And our English teaching, in fact, is the process of second language acquisition in the context of non-target language. Adequate language input is the necessary premise and foundation for all expressions and practical activities. If the language learners are lack of "output" in practice, language knowledge and information will only stay in the memory stage and the knowledge cannot be internalized by the learners, it also cannot achieve the ultimate goal of language as a tool to convey information and express ideas. Throughout our country, foreign language teaching, especially English teaching, has always been characterized by "heavy input" and "light output". However, due to time limitation and other reasons, students cannot get the necessary practice opportunities. Therefore, the "output" has been unable to play its proper role in helping learners internalize their target language knowledge. This is also an important reason why many students devote a lot of energy to English learning but cannot achieve corresponding results.

In order to make the language classroom input and output organically, Wen Quang, distinguished Chinese linguists and foreign language educator, in 2008, proposed the "output driven hypothesis". The main content includes the following three aspects: first, from the driving force of learning, it seems that output has more driving force than input. High quality input is limited in the absence of effective output practices. Second, from the social requirements for talents, workplace English emphasize more on the students' ability to speak, write and translate, and the expressive skills will play a more obvious role in the employment of students. Third, from the aspect of foreign language teaching, the output oriented comprehensive teaching method is more effective than the single specific skill training method, and more conducive to the development of students' comprehensive language ability.

\section{The Characteristics of Teaching of English for Science and Technology Writing}

With the rapid development of society and the continuous progress of science and technology, the development of science and technology is becoming more and more specialized and profound. The arrival and deepening of the era of high technology and information technology also make scientific English play an increasingly important role in international scientific and technological cooperation, communication and dissemination. Strictly speaking, science and technology, which we all know today, is actually a functional variant of modern English applied to the field of science and technology. It is formed with the progress and development of science and technology. Therefore, English for science and technology (EST) has its own unique aspects with such as vocabulary, syntax, language style and classic expression, which is quite different from social English and general English concentrated by us. The main features of scientific and technical language include that they are accurate, clear, rigorous, objective, factual and logical, which also meet the language requirement of EST. In the scientific literature, in order to express the accuracy and objectivity of science, the writers are always required to use normative and formal expression to state the scientific dogma and law, describe the process of the development of objects, and illustrate the cause and effected. Because of the high demands for the requirements of qualified personnel in modern times, accuracy of English writing plays more and more important roles for learners, which means that college English teachers must get a better and more effective way to improve students' English writing (Rong Yingying, 2011).

In the course of our current English teaching, the courses of science and technology English are set up on the basis of students' certain language. Most of the courses are offered in the graduate study stage. Its purpose is to make the course play the role as a bridge, make a rapid transition for the learners to learn a specialized field of knowledge, carry out professional research or engage in a professional career through the bridge of the general English learning. With the purpose above, the teaching focus has changed. Previously, our teaching system emphasize more on language learning and cultivate practical ability in English in everyday situations. While the key EST lies in the thinking process and the way to guide students to be familiar with and grasp the application of language. With the help of classroom learning and practice, it can enable students to use the knowledge in practice activities and work. Because of its different teaching purposes and emphases, the teaching strategies will change accordingly. EST writing is a specialized English category with 
specialized knowledge as its core. It is not only the extension of basic English writing, but also the process of using it. Therefore, scientific and technical English writing course must pay attention to the organic combination of classroom teaching and practical activities, and emphasize the implementation of practical teaching. In the process of writing, they may try to use the words, phrases, sentence patterns or writing strategies learnt in reading class (Li Dayan, 2012).

\section{3. "Output Driven" Hypothesis and Its Implications for EST Writing}

In view of the students who have certain English proficiency, the relationship between input and output should be well dealt with in the course of scientific English writing.It is suggested that teachers should focus on output to drive input in teaching activities, and actively guide students to input language accurately and rapidly into language output. Teachers could combine professional vocabulary, knowledge, thinking ability and English writing ability.

\subsection{Take the Student as the Main Body.}

EST writing is more of a practical course. A large number of practical activities are the main guarantee for improving students' Comprehensive English skills. Therefore, the role of teachers must be changed to make certain conversion, design, organize and assist to offer more emphasis on classroom activities. Teachers should focus more on language input. Skills explanation are necessary to be explained as much as possible with the output.

\subsection{Comprehensive Design Course.}

Listening, speaking, reading, writing and translating are five basic skills of language. Listening and reading are input skills, and speaking, writing and translating are output skills. These five skills cannot be separated, and they are closely related and influence each other. Only when output was attached more importance to can input be freely. With no output driven input, it cannot make the learners learn the input effectively. This requires teachers that they should consider five skills training comprehensively, and design of each module of classroom teaching rationally in teaching activities.

\subsection{Increase the "Output" Channel.}

Scientific and technical English writing is different from our traditional Band Four and Band Six English test oriented traditional writing teaching, it also involves the acquisition of professional content. It is a technical, cross and highly professional courses. Most technical English writing courses are taught by non-English majors, with limited periods. In order to achieve good teaching results, teachers should make full use of classroom teaching time, and actively create opportunities for students to increase output opportunities for practice. Under certain circumstances, it can also be combined with professional courses, and should be guided by specialized courses to increase the students' practice of output.

\section{Conclusion}

EST writing is a very important course, which plays an important role in the communication and communication of science and technology. At the same time, it is a special course in which the learners, the center of learning and the teaching aim are greatly different from the traditional English teaching. Under the guidance of “output driven hypothesis”, teachers in colleges and universities should design practice effectively, let learners absorb, master language knowledge with the output driven, guide students to actively carry out reflection, and train students' independent learning ability.

\section{References}

[1]. Yang Ye, Yuan Ping. A Comparative Study of Input Hypothesis and Output Hypothesis [J]. 
Read and Write Periodical, 2010,7.

[2]. Rong Yingying. Implications of Output Hypothesis on College English Writing [J]. Overseas English, 2010, 12.

[3]. Li Dayan, Wang Jianan. On Reading-Based Writing Instruction Model [J]. Read and Write Periodical, 2012, 2. 